GDS was a Wellcome fellow in clinical epidemiology when the fieldwork for this study was completed.

Conflict of interest: None.

1 M'Gonigle GCM, Kirby J. Poverty and public health. London: Golantz, 1936.

Morris JN, Titmuss RM. Health and social change: recent history of rheumatic heart disease. Medical Officer 1944;2:69-71, 77-9, 85-7.

3 Moser KA, Fox AJ, Jones DR. Unemployment and mortality in the OPCS longitudinal study. Lancet 1984;ii:1324-9.

4 Morris JK, Cook DG, Shaper AG. Loss of employment and mortality. BMF 1994;308:1135-9.

5 Beale N, Nethercott S. Job-loss and family morbidity: a study of a factory closure. I R Coll Gen Pract 1985;35:510-4.

6 Cook DG, Cummins MJ, Bartley MJ, Shaper AG. The health of unemployed middle aged men in Britain. Lancet 1982;i:1290-4.

7 D'Arcy C, Siddique CM. Unemployment and health: an analysis of "Canada Health" data. Int $f$ Health Serv 1985;15:609-35.

8 Jahoda M, Lazarsfeld P, Zeisel H. Marienthal: the sociography of an unemployed community. London: Tavistock, 1972.

9 Warr P, Jackson P, Banks M. Unemployment and mental health: some British studies. Fournal of Social Issues 1988;44:47-68.

10 Platt SD, Kreitman N. Trends in parasuicide and unemployment among men in Edinburgh 1968-82. BMY 1984;289:1029-32.

11 Organisation for Economic Cooperation and Development. The OECD jobs study - facts, analysis and strategy. Paris: OECD, 1994.

12 Cobb S, Kasl SV. Termination: the consequences of job loss. Cincinatti: Nationa Institutes for Occupational Safety and Health, 1977. (DHEW-NIOSH publication No 77-224.)

13 Hamilton VL, Broman CL, Hoffman WS, Renner DS. Hard times and vulnerable people: initial effects of plant closing on autoworkers' mental health. Fournal of Health and Social Behaviour 1990;31:123-40.

14 Morris JK, Cook DG. A critical review of the effect of factory closures on health. Br f Ind Med 1991;48:1-8.

15 Marmot MG, Davey Smith G, Stansfeld S, Patel C, North F, Heald J, et al. Health inequalities among British civil servants: the Whitehall II study. Lancet 1991;337:1387-93.

16 Cabinet Office. Civil service yearbook 1994. London: HMSO, 1994

17 Treasury Efficiency Unit. Using private enterprise in government. London: HMSO, 1986.
18 Bill P. Government to sell off PSA construction arm. Building 1988; December 2:7.

19 Walker D. Financial rule eased to assist PSA sale. Times 1989;December 6:4 20 Guest P. Staff cuts to trim pre-privatised PSA. Building 1989;December 8:10.

21 Kitchen S. PSA facts and figures. Building 1989;August 25:5.

22 Bill P. Cabinet ministers clash over PSA control. Building 1988;March 18:5.

23 Office of Population Censuses and Surveys. General household survey 1977. London: HMSO, 1979 .

24 Hennessy P. Whitehall. London: Fontana, 1990.

25 Stansfeld SA, Marmot MG. Social class and minor psychiatric disorder in British civil servants: a validated screening survey using the general health questionnaire. Prychol Med 1992;22:739-49.

26 Glynn RJ, Rosner B, Silbert JE. Changes in cholesterol and triglyceride as predictors of ischemic heart disease in men. Circulation 1982;66:724-31.

27 Cain KC, Kronmal RA, Kosinski AS. Analysing the relationship between change in a risk factor and risk of disease. Statistics in Medicine 1992;11:78397.

28 Beale $N$, Nethercott $S$. The health of industrial employees four years after compulsory redundancy. $¥ R$ Coll Gen Pract 1987;37:390-4.

29 Idler EL, Kasl S. Health perceptions and survival-do global evaluations of health-status really predict mortality. $f$ Gerontol 1991;46:55-65S.

30 Kasl SV. Changes in mental health status associated with job loss and retirement. In: Barrett JE, ed. Stress and mental disorder. New York: Raven Press, 1979:179-200.

31 Hartley J, Jacobson D, Klandermans B, Van Vuuren T. fob insecurity: coping with jobs at risk. London: Sage, 1991.

32 Burchell B. The effects of labour market position, job insecurity, and unemployment on psychological health. In: Gallie D, Marsh C, Vogler C, eds. Social change and the experience of unemployment. Oxford: Oxford University Press, 1994:188-212.

33 Stansfeld SA, Davey Smith G, Marmot MG. Association between physical and psychological morbidity in the Whitehall II study. I Psychosomatic Res 1993;37:1-12.

34 Mattiasson I, Lindegarde F, Nilsson J, Theorell T. Threat of unemployment and cardiovascular risk factors: longitudinal study of quality of sleep and and cardiovascular risk factors: longitudinal study of quality of sleep and 1990;301:461-6.

35 Grayson JP. Health, physical activity level and employment status in Canada. Int F Health Serv 1993;23:743-61.

(Accepted 20 August 1995)

\title{
Bed sharing and the sudden infant death syndrome
}

\author{
Hillary Klonoff-Cohen, Sharon L Edelstein
}

Abstract

Objective-To determine whether infants who died of the sudden infant death syndrome routinely shared their parents' bed more commonly than control infants.

Design-Case-control study.

Setting-Southern California.

Subjects-200 white, African-American, Latin American, and Asian infants who died and 200 living controls, matched by birth hospital, date of birth, sex, and race.

Main outcome measures-Routine bedding (for example, crib, cradle), day and night time sleeping arrangement (for example, alone or sharing a bed); for cases only, sleeping arrangement at death. Differences in bed sharing practices among races.

Results-Of the infants who died of the syndrome,

Department of Family and Preventive Medicine, Division of Epidemiology, University of California, San Diego, La Jolla, CA 92037-0607, United States Hillary Klonoff-Cohen, assistant professor

George Washington Biostatistical Center, George Washington University, Rockville, $M D$ 28052

Sharon L Edelstein, senior scientist

Correspondence to: Dr Klonoff-Cohen.

BMF1995;311:1269-72 45 (22.4\%) were sharing a bed. Daytime bed sharing was more common in African-American $(P<0.001)$ and Latin American families $(P<0.001)$ than in white families. The overall adjusted odds ratio for the syndrome and routine bed sharing in the daytime was $1.38(95 \%$ confidence interval 0.59 to 3.22$)$ and for night was $1.21(0.59$ to 2.48$)$. These odds ratios were adjusted for routine sleep position, passive smoking, breast feeding, intercom use, infant birth weight, medical conditions at birth, and maternal age and education. There was no interaction between bed sharing and passive smoking or alcohol use by either parent.

Conclusions-Although there was a significant difference between bed sharing among AfricanAmerican and Latin American parents compared with white parents, there was no significant relation between routine bed sharing and the sudden infant death syndrome.

\section{Introduction}

Reasons for bed sharing emerge from evolutionary, developmental, and cross cultural perspectives. Parental sleep contact promotes sleep, breathing, and arousal patterns in infants, ${ }^{1}$ and parents and infants who sleep together exhibit synchronous arousals ${ }^{12}$ and coordination of sleep stages. ${ }^{23}$ The composition of human milk also supports bed sharing; its low energy value causes infants to feed on demand throughout the day and night. ${ }^{2}$

Despite its reported benefits, bed sharing has also been linked to an increased risk of the sudden infant death syndrome. Mitchell et al ascribed such deaths to sleeping with adults, which may overheat infants. ${ }^{4} \mathrm{~A}$ case-control study in England found that bed sharing was more common in cases than controls. ${ }^{5}$ A nationwide case-control study in New Zealand found a twofold increase in the risk of the sudden infant death syndrome associated with sharing a bed ${ }^{6}$; further analyses by Scragg et al, however, found that bed sharing before death was a risk factor only among Maori infants. ${ }^{7}$ There was an interaction between bed sharing and maternal smoking on an additive scale (odds ratio=5.94). A postal survey of 197 infants in southern Australia suggested that a parent's alcohol consumption the night before the death may be a cofactor with bed sharing. ${ }^{8}$ A study of 92 cases and 100 controls in the District of Columbia found a threefold excess rate over the general population for bed sharing and the risk of the sudden infant death syndrome. ${ }^{9}$ The authors surmised this was due to asphyxia from overlaying, possibly combined with parental consumption of alcohol or drugs.' A survey of Asian and white mothers by Faroqui et al did not support the hypothesis that bed sharing increased the risk of the sudden infant death syndrome. ${ }^{10}$ Asian infants were more 
likely to share the parents' bed but less inclined to be exposed to passive smoke than white infants. Nevertheless, white infants had twice the mortality from the sudden infant death syndrome, compared with Asian infants. To our knowledge, there are no other studies investigating bed sharing and the sudden infant death syndrome.

It is difficult to conclude that sharing a bed is dangerous across all cultures. The lowest rates of the syndrome occur in Asia, especially Japan, where sharing a bed is common. ${ }^{11}$ In New Zealand, however, where bed sharing occurred on sheepskin bedding or in the presence of maternal smoking, rates were extremely high before the introduction of the "lower risk" campaign.

We examined the relation between routine bed sharing and bed sharing at the time of death and the sudden infant death syndrome in a case-control study of 200 case and 200 control white, Latin American, Asian (Chinese, Filipino, Vietnamese, Japanese, Korean, Samoan, Burmese, Guamanian, Hawaiian) and Pacific Islander, and African-American infants in southern California.

\section{Methods}

Cases attributed to the syndrome were obtained from death certificates from five health departments in southern California (San Diego, San Bernardino, Riverside, Orange, and Los Angeles counties). All case infants had undergone necropsy at death between January 1989 and December 1992. Parents of infants whose death was attributed to the syndrome were contacted by post for participation in the study six to 12 months after the death, the grief period required by the Human Subjects Committee.

Control infants were randomly selected (by using a random number table and identification numbers) from all eligible live born infants in 110 southern California hospitals. Each control infant had the same birth hospital, date of birth, sex, and race as the matched case infant. Directors of medical records departments initially contacted prospective control parents by post. Control parents were contacted about three to six months after the case interview. A history of infant care practices (for example, routine sleep position, illnesses, vaccinations, and breast feeding) was obtained when the control baby was the same age as the index case.

Infants with respiratory problems, fetal distress, metabolic disturbances, and morphological abnormalities were not included in the study. Multiple births, infants over 1 year of age, adopted babies, and cases in which necropsy was not undertaken were excluded from the study.

Parents of infants who died and control parents provided written informed consent for the interview and access to obstetric and paediatric records. Parents then participated in a 45 to 60 minute standardised telephone interview, which provided demographic information, obstetric history, information on labour and delivery, neonatal characteristics, parental lifestyle, family history of diseases, and circumstances of death for cases. Parents also reported routine place of sleeping for the infant-specifically, a crib, carrycot, pram, cradle, swing, parents' or other person's bed, couch, floor, or other place-for both day and night. The infant's sleeping arrangement was noted, specifically if he or she slept in the same room as a parent or alone in another room. Bed sharing was defined as routinely sharing a bed with a specified person, including the mother, father, other relative (sibling, aunt, grandparent, etc), or babysitter during the day or night. Infants who had a combination of bed sharing and sleeping alone were separately noted.
Routine sleep position was classified as on the stomach, back, or side; alternating between any two positions; or no usual position. Regular use of an intercom was reported. Feeding history included exclusive breast feeding, formula milk, or both breast and formula milk, and the frequency of feeding each day from birth. Passive smoking was based on cigarette smoking by the mother, father, live in adult, or daycare provider. The infant's birth weight and any medical condition at birth were recorded (for example, jaundice, apnoea, fever, aspiration of meconium).

The infant's race was categorised on the basis of both parents' races. Babies with both parents of the same race were assigned that race. When one parent was white and the other parent was Asian, Latin American, or African-American the baby was assigned the race of the minority parent, in accordance with the guidelines from the United States government on vital statistics. ${ }^{12}$ If both parents were different minority races, the baby was assigned the race with the smallest representation in California.

\section{STATISTICAL ANALYSES}

Preliminary analysis was based on the first 200 case and 200 matched control parents interviewed before the height of publicity in the United States about sleep position. Three hundred cases and 300 controls were interviewed for this study, out of a total of 400 case and 400 control parents. About $2 \%$ of parents of children who died and $1.3 \%$ of control parents refused to participate.

Conditional logistic regression was used to estimate independently the odds ratio of the syndrome associated with bed sharing in the day and night with simultaneous adjustment for potential confounders. Stratified analysis and published data were the criteria used for adding variables to the logistic regression model. Descriptive analyses were computed by using the statistical software package $\mathrm{SAS}^{13}$; multivariate analyses used EGRET. ${ }^{14}$

\section{Results}

Parents of infants who died were about three years younger than parents of healthy babies (26 years and 28 years for case mothers and fathers, respectively; $\mathrm{P}<0.001$ ), and education levels for fathers of infants who died were slightly lower than for control fathers $(12.5 v 13.4$ years; $P<0.01)$. More parents of healthy infants were married or living together than parents of infants who died $(77 \% v 63 \%$, respectively; $\mathrm{P}<0.01)$. The total racial distribution of babies in the two groups was approximately $48 \%$ (192) white, $30 \%$ (120) Latin American, 11\% (44) Asian and Pacific Islander, 10\% (40) African-American, and 1\% (4) North American Indian. All mothers had their pregnancies confirmed during the seventh week of gestation. There was no significant difference between the proportion of the mothers in each group who received prenatal care (175 (cases) $v 185$ (controls)). Infants who died had significantly lower birth weights than control infants $(3236 \mathrm{~g}$ $v 3459 \mathrm{~g} ; \mathrm{P}<0.001$ ).

There was no difference in age (categorised as $\leqslant 20$ years and $>20$ years) between case or control mothers who chose for their infant to share a bed and those whose infants slept alone. Mothers who slept with their infants, however, were less educated ( $\leqslant 12$ years in total) than mothers whose infants slept alone $(P=0.02$ for cases; $P<0.01$ for controls).

Routine bed sharing was assessed independently for day and night. Daytime bed sharing was most common in African-American and Latin American families compared with white households. African-American controls and Asian cases were more likely than white infants to share a bed at night (table I). 
TABLE -Number (percentage) by racial category of 200 children who died from the sudden infant death syndrome and 200 controls routinely sharing a bed with adult in day or night: southern Califormia, 1989-92

\begin{tabular}{|c|c|c|c|c|c|c|c|c|}
\hline \multirow[b]{3}{*}{ Race } & \multicolumn{4}{|c|}{ Cases } & \multicolumn{4}{|c|}{ Controls } \\
\hline & \multicolumn{2}{|c|}{ Day } & \multicolumn{2}{|c|}{ Night } & \multicolumn{2}{|c|}{ Day } & \multicolumn{2}{|c|}{ Night } \\
\hline & No & $(\%)$ & No & (\%) & No & (\%) & No & $(\%)$ \\
\hline $\begin{array}{l}\text { White } \\
\text { African-American } \\
\text { Latin American } \\
\text { Asian } \\
\text { Native American }\end{array}$ & $\begin{array}{r}10 \\
11 \\
22 \\
6 \\
1\end{array}$ & $\begin{array}{l}(10 \cdot 4) \\
(57 \cdot 9)^{\star \star \star} \\
(39 \cdot 3)^{\star \star} \\
(26 \cdot 1)^{\star} \\
(50)\end{array}$ & $\begin{array}{r}20 \\
9 \\
24 \\
7 \\
0\end{array}$ & $\begin{array}{l}(20 \cdot 8) \\
(47 \cdot 4)^{\star} \\
(42 \cdot 9)^{\star \star \star} \\
(30 \cdot 4)\end{array}$ & $\begin{array}{r}9 \\
8 \\
18 \\
1 \\
0\end{array}$ & $\begin{array}{c}(9 \cdot 5) \\
(40)^{\star \star \star} \\
(29 \cdot 5)^{\star \star \star} \\
(5 \cdot 3)\end{array}$ & $\begin{array}{r}14 \\
11 \\
25 \\
2 \\
0\end{array}$ & $\begin{array}{l}(14 \cdot 7) \\
(55)^{\star \star \star} \\
(41)^{\star \star \star} \\
(10 \cdot 5)\end{array}$ \\
\hline
\end{tabular}

$\star \mathrm{P}<0.05 ; \star \star \mathrm{P}<0.01 ; \star \star \star \mathrm{P} \leqslant 0.001$.

TABLE II-Sleep location at time of death in 200 cases of the sudden infant death syndrome, southern California, 1989-92

\begin{tabular}{lc}
\hline Location & No of children \\
\hline Crib & 81 \\
Pram & 41 \\
Sharing parents' bed & 35 \\
Cradle & 8 \\
Couch & 7 \\
Babysitter's bed & 6 \\
Mother's arms & 4 \\
Swing & 4 \\
Floor & 4 \\
Playpen & 3 \\
Folding bed & 1 \\
Wool mat & 1 \\
Cushion or pillow & 1 \\
Baby carrier & 1 \\
Waterbed & 1 \\
Unknown & 2 \\
\hline
\end{tabular}

Fifty of the infants who died and 36 controls routinely shared a bed during the daytime $(P=0 \cdot 11)$, whereas in the night bed sharing occurred in 60 cases and 52 controls $(P=0.36)$ (table II).

At death, 45 infants were sharing a bed with a parent (35 sleeping together, four sleeping in mother's arms) or babysitter (six) (table I); the remainder were reported as sleeping alone.

Case infants who shared a bed with a parent were more likely to have been exposed to passive smoke than infants who slept alone during the day and night. Control infants who vomited after feeds were less likely to share a bed $(P=0.028)$. Parents in both groups who had shared with their infant were less likely to use an intercom ( $P=0.012$ for cases in daytime and night; $P<0.01$ for controls for daytime only).

The relation between bed sharing and the syndrome did not differ by race; in fact the odds ratio for night was higher in whites than non-whites $(1.52 v 1.12)$ whereas for daytime it was reversed $(1 \cdot 11$ for whites and 1.78 for non-whites), indicating no consistent pattern. Case and control babies who routinely shared a bed did not significantly differ by sleep position, breast feeding, use of pacifiers, ease of waking from sleep, or irregular breathing. Bed sharing did not vary by season. During the day low birthweight case infants who later died were more likely to share a bed $(P=0.014)$.

The unadjusted odds ratio for the syndrome and bed sharing for daytime was 1.52 (95\% confidence interval 0.92 to 2.52$)$; for night it was $1.28(0.81$ to 2.03$)$. The overall adjusted odds ratio was $1.38(0.59$ to 3.22$)$ for routine bed sharing during the day, and $1.21(0.59$ to $2 \cdot 48$ ) for routine bed sharing during the night after adjustment for routine sleep position, birth weight, medical conditions at birth, passive smoking, exclusive breast feeding, intercom use, and maternal age and education (table III). Maternal prenatal care did not substantially alter the odds ratio (daytime $1.39(0.61$ to $3 \cdot 15)$, night $1.22(0.60$ to $2 \cdot 50)$ ).

When maternal alcohol and recreational drug use were independently added to the model the odds ratios for bed sharing during the day and night remained virtually unchanged. There were no interactive effects between bed sharing and passive smoking, alcohol, or recreational drugs.

\section{Discussion}

There is great controversy about bed sharing and the sudden infant death syndrome. Our study confirmed that significantly more Latin American and AfricanAmerican parents and infants than white families routinely slept together. For infants who died from the syndrome 45 deaths occurred while sharing a bed. There was a weak association between bed sharing and the sudden infant death syndrome (odds ratio $1 \cdot 21$ night, 1.38 day), which was not significant when potential confounders were adjusted for. In our study bed sharing was not a major risk factor for the syndrome. Sample size calculations indicate that 200 matched sets would require an odds ratio of 2.9 for a significance level of $P<0.05$ and $80 \%$ power.
Five studies have reported that bed sharing, usually in combination with maternal smoking or alcohol consumption, was a risk factor for the sudden infant death syndrome..$^{5-9}$ We found no interactive effect between bed sharing and maternal use of alcohol, tobacco, or recreational drugs. In contrast, studies based solely on Asian populations reported lower rates of the syndrome with bed sharing. ${ }^{15-18}$

Unlike the aforementioned studies, our study accounted for routine bed sharing during the day and night. The comparison of routine bed sharing rather than sharing just at the time of death reduced the risk of confounding due to illness. Bed sharing at death was independently ascertained rather than using bed sharing over the last two weeks of life as a routine measure of bed sharing. ${ }^{7}$ In previous studies control infants were absent ${ }^{8}$ or poorly selected. ${ }^{9}$ Most importantly, adjustment for salient maternal and infant characteristics was not performed in other studies. ${ }^{5810}$ We adjusted for confounders not dealt with previously, ${ }^{18}$ including passive smoking, intercom use, maternal education, recreational drug use, and any neonatal medical conditions. Diagnoses of the sudden infant death syndrome differed between this study and that of Scragg et al, which included infants with abnormalities, ${ }^{7}$ and Carpenter's, which included infants up to 2 years of age and had an $80 \%$ necropsy rate. ${ }^{5}$ To our knowledge, although Scragg et al compared bed sharing among Maori and Pacific Islanders, ${ }^{7}$ ours is the first study to examine it among four racial groups in the United States.

Recall bias may have been a problem in this study because the Human Subjects Committee required a delay before we interviewed case parents. A subsample $(50 \%)$ of interviews with parents of infants who died was compared with reports from the scene of death, and the agreement rate was very high. In addition, 10 mothers and fathers from each group underwent separate interviews, resulting in a very high agreement rate for all infant characteristics and information at the scene of death. Furthermore, control infants may have been older than their corresponding cases when their parents were interviewed. Each control infant's age corresponded to the case infant's age for particular events including vaccinations, illnesses, and breast feeding practices. During the interview, the sleeping arrangement during infancy was always specified. Recall bias was minimised because bed sharing was not the primary hypothesis, a standardised interview was used for all parents, and great attention was devoted to the interview technique, including ordering of questions based on a time line corresponding with life events from pregnancy through birth.

Although bed sharing occurs in about $90 \%$ of the world population, western industrialised societies consider solitary infant sleep a normal and desirable arrangement. ${ }^{3}$ In fact, infants are expected to exhibit adult sleep profiles by 3-4 months of age. ${ }^{19}$ There are, however, potential benefits to bed sharing. Parents sleeping with their infants inadvertently provide stimulation through vocalisations, body move-

TABLE II-Unadjusted and adjusted odds ratios (95\% confidence interval) for the sudden infant death syndrome associated with routine day and night bedsharing; southern California, 1989-92 (200 cases, 200 controls)

\begin{tabular}{lc}
\hline Detail & $\begin{array}{c}\text { Odds ratio } \\
\text { (95\% confidence interval) }\end{array}$ \\
\hline Unadjusted day & $1.52(0.92$ to 2.52$)$ \\
Unadjusted night $_{\text {Adjusted day }}^{\star}$ & $1.28(0.81$ to 2.03$)$ \\
Adjusted night $^{\star}$ & $1.38(0.59$ to 3.22$)$ \\
& $1.21(0.59$ to 2.48$)$
\end{tabular}

*Adjusted for routine sleep position, passive smoking, breast feeding, use of intercom, maternal age and education, infant birth weight, and any medical conditions at birth. 


\section{Key messages}

- A total of 200 case and 200 control infants were compared for type of bed and sleeping arrangement (for example, alone or sharing a bed) during the day and night

- Bed sharing during the day was more common in African-American and Latin American families than white families

- Forty five $(22 \cdot 4 \%)$ deaths occurred in infants who were sharing a bed

- There was lack of evidence of an effect between bed sharing during the day and night and the sudden infant death syndrome

- Future larger studies should investigate unknown physiological or behavioural risk factors of bed sharing and the sudden infant death syndrome

ments, radiant heat, respiratory sounds, odours, and possibly expired gases. ${ }^{3}$ Infants who share the parents' bed arise more frequently and simultaneously with the mother and spend less time in stage three to four of quiet sleep. ${ }^{3}$

Although the cause of the sudden infant death syndrome is multifactorial, contemporary hypotheses include defects in arousal or cardiorespiratory control. ${ }^{20}$ If bed sharing were protective for the sudden infant death syndrome it might override potentially fatal breathing errors or decreasing arousal deficits. ${ }^{21}$ In contrast, bed sharing may increase the risk of the syndrome through accidental suffocation by overlaying or hyperthermia. ${ }^{6}$ In this study, there was little evidence of an effect of bed sharing on the syndrome. Additional prospective studies are required to determine whether other unknown physiological or behavioural risk factors associated with sharing a bed may increase the risk of the sudden infant death syndrome.

We thank Karen Wiley for her assistance and Randy Cohen and Kella Svetich-McWalter for their editorial comments.
Funding: This research was supported by grants 1KT0038 and 2KT0063 from the University of California, TobaccoRelated Disease Research Program.

Conflict of interest: None.

1 McKenna J, Mosko S, Dungy C. Sleep and arousal patterns of co-sleeping human mother/infant pairs: a preliminary physiological study with implications for the study of sudden infant death syndrome. Am $\mathcal{F}$ Phys Anthropol 1990;83:331-47.

2 McKenna J, Mosko S. Evolution and infant sleep: an experimental study of infant-parent co-sleeping and its implications for SIDS. Acta Paediatr Suppl 1993;389:31-4.

3 Mosko S, McKenna J, Dickel M, Hunt L. Parent-infant co-sleeping: the appropriate context for the study of infant sleep and implications for sudden infant death syndrome research. $₹$ Behav Med 1993;16:589-610.

4 Mitchell E, Scragg R, Stewart A, Bencroft, D, Ford R, Hassall I, et al. Results from the first year of the New Zealand cot death study. $N Z$ Med $\mathcal{F}$ 1991;104:71-4.

5 Carpenter R. Sudden and unexpected deaths in infancy. In: Camps $F$, Carpenter $\mathbf{R}$, eds. Sudden and unexpected deaths in infancy. Bristol: John Wright, 1972:7-15.

6 Mitchell E, Taylor R, Ford R, Stewart A, Becroft A, Thompson J. Four modifiable and other major risk factors for cot death: the New Zealand study. I Paediatr Child Health 1992;28(suppl 1):53-8.

7 Scragg R, Mitchell E, Taylor B, Stewart A, Ford R, Thompson J, et al. Bed sharing, smoking, and alcohol in the sudden infant death syndrome. $B M Y$ 1993;307:1313-8.

8 Bourne A, Beal S, Byard J. Bed sharing and sudden infant death syndrome. $B M F$ 1994;308:537-8.

9 Luke J. Sleeping arrangements of sudden infant death syndrome victims in the District of Columbia-a preliminary report. If Forensic Science 1977;23: 379-83.

10 Faroqui I, Lip G, Beevers D. Bed sharing and smoking in the sudden infant death syndrome. $B M f$ 1994;308:204-5.

11 Tasaki $H$, Yamashita $M$, Mihazaki $S$. The incidence of SIDS in SAGA prefecture (1981-1985). Fournal of the Paediatric Association of Fapan $1992 ; 364-8$.

12 United States Department of Commerce, Monthly vital statistics repont supplement. Hyattsville, MD: US Department of Commerce, 1989.

13 SAS Institute. SAS user's guide: statistics. Version 6, 4th edition. Cary, NC SAS Institute, 1990.

14 Epidemiological Resources Incorporated. EGRET: epidemiological graphics, estimation and testing. Seattle, WA: Epidemiological Resources, 1993.

15 Davies D. Cot death in Hong Kong: a rare problem? Lancet 1985;ii:1346-8.

16 Lee N, Chan Y, Davies D, Lau E, Yip D. Sudden infant death syndrome in Hong Kong: confirmation of low incidence. $B M F$ 1989;298:721.

7 Mitchell E, Stewart A, Scragg R, Ford R, Taylor B, Becroft D, Ethnic differences in mortality from sudden infant death syndrome. in New differences in mortality from

18 Mitchell E, Scragg R. Are infants sharing a bed with another person at increased risk of sudden infant death syndrome? Sleep 1993;16:387-9.

19 Hoppenbrouwers T, Hodgman J, Harper R, Sterman M. Temporal distribution of sleep states, somatic activity, and autonomic activity during the first half year of life. Sleep 1982;5:131.

20 Guntheroth W. Crib death: the sudden infant death syndrome. Mount Kisco, NY: Future, 1989

21 Konner M, Super C. Sudden infant death: an anthropological hypothesis. In Suyer C, Harkness S eds. The role of culture in developmental disonder. New York: Academic Press, 1987.

(Accepted 20 August 1995)

Style Matters

\title{
Protection of patients' rights to privacy
}

\author{
International Committee of Medical Journal Editors
}

The following statement was agreed by the International Committee of Medical fournal editors (the Vancouver Group) at its meeting last week in San Francisco. It is a complete revision of the initial guidelines on this subject issued in 1991.

Patients have rights to privacy that should not be infringed without informed consent. Identifying information should not be published in written descriptions, photographs, or pedigrees unless the information is essential for scientific purposes and the patient (or parent or guardian) gives written informed consent for publication. Informed consent for this purpose requires that the patient should be shown the manuscript to be published.

Identifying details should be omitted if they are not essential, but patient data should never be altered or falsified in an attempt to attain anonymity. Complete anonymity is difficult to achieve, and informed consent should be obtained if there is any doubt. For example, masking of the eye region in photographs of patients is inadequate protection of anonymity.

The requirement for informed consent should be included in the journal's instructions for authors. When informed consent has been obtained it should be indicated in the published article.

Members of the committee are: Frank Davidoff (Annals of Internal Medicine), Richard Smith (BMF), Bruce P Squires (Canadian Medical Association foumal), George Lundberg, Richard Glass $(\mathcal{F} A M A)$, Richard Horton (Lancet), Martin Van Der Weyden (Medical foumal of Australia), Robert Utiger (New England foumal of Medicine), Richard G Robinson (New Zealand Medical fournal), Magne Nylenna (Tidsskrift for den Norske Laegeforening), Linda Clever (Western Medical fournal), Lois Ann Colaianni (National Library of Medicine). 